\title{
Los juegos de poder en la cibercultura. Una investigación sobre los usos estratégicos de la lectura y la escritura que hacen estudiantes universitarios en la red
}

POWER GAMES IN CYBERCULTURE. AN INVESTIGATION OF THE STRATEGIC USES OF READING AND WRITING THAT MAKE COLLEGE STUDENTS IN THE NETWORK

OS JOGOS DE PODER NA CIBERCULTURA. UMA INVESTIGAÇÃO SOBRE OS USOS ESTRATÉGICOS DA LEITURA EA ESCRITURA QUE FAZEM ESTUDANTES UNIVERSITÁRIOS NA REDE

\section{Martha Helena Barreto R* / marthab30@gmail.com \\ Giselle Castillo Hernández** gcastillohernandez1@gmail.com}

\section{Resumen}

El artículo presenta los resultados de la investigación a partir del análisis de la encuesta a un grupo de estudiantes universitarios y de la profundización a través de una entrevista focal. Se asume una posición crítica para demostrar cómo el uso estratégico del lenguaje en la cibercultura es aquel que se realiza con el fin de incidir en la acción del otro, en tanto que el uso depende del sujeto y del papel que lo acompaña, pues todo discurso está revestido de poder. Se concluye que el sujeto es productor de discurso y la comunicación en las redes genera nuevas formas de subjetividad.

\section{Summary}

The article shows the research results from the student's survey and the deepening trough a focal interview. A critical position is assumed to show how the strategic use of language in cyberculture is the one which is made to influence on the others action, given that the use depends on the subject and the role that accompanies him, since every speech is coated of power. It is concluded that the subject is the speech producer and the communication in networks produces new subjectivity forms.

\section{Resumo}

O artigo mostra os resultados da investigação partido do análise da enquête feita a um grupo de estudantes universitários e a aprofundação por meio de uma entrevista focal. É assumida uma posição critica pra mostrar como o uso estratégico da linguagem na cibercultura e aquele que é realizado com o fim de incidir na ação do outro, enquanto o uso depende do sujeito e do papel que o acompanha, já que todo o discurso esta revestido de poder. A conclusão é que o sujeito é produtor de discursos e a comunicação nas redes gera novas formas de subjetividade.

\section{Palabras clave}

Cibercultura, lenguaje, poder, lectura, escritura.

\section{Key Words}

Cyberculture, language, power, reading, writing.

\section{Palavras chave}

Cibercultura, linguagem, poder, leitura, escritura.

* Profesora de planta, Universidad Distrital Francisco José de Caldas. Socióloga, Magister en Desarrollo Social y Humano. CINDE-UPN y Filosofía. Pontificia Universidad Javeriana. Investigadora principal de la investigación Los usos estratégicos de la lectura y la escritura en la red. Miembro del grupo: Lenguaje, discurso y saberes, de la Facultad de Educación de esta universidad.

** Profesora de vinculación especial, Universidad Distrital Francisco José de Caldas. Licenciada en Ciencias Sociales, Universidad Pedagógica Nacional. Magíster en Sociología, Universidad Nacional de Colombia. Co-investigadora.

Fecha de recepción: 10 de septiembre de 2012 / Fecha de aprobación: 18 de octubre de 2012 


\section{Introducción}

La investigación "Usos estratégicos de la lectura y la escritura en la red", desarrollada con estudiantes del proyecto curricular de Pedagogía Infantil de la Universidad Distrital Francisco José de Caldas, durante el período 2009-2010, se inscribe en la producción del grupo Lenguaje, Discurso y Saberes, adscrito a la Facultad de Ciencias y Educación. Esta investigación, busca problematizar, desde una perspectiva crítica, las relaciones entre ciencia, tecnología y sociedad, para preguntar cómo la cibercultura se encuentra asociada con agenciamientos de vida, trabajo y lenguaje. Se plantea una metodología cualitativa, en tanto que busca identificar el uso estratégico de la lectura y la escritura a través de la experiencia de los sujetos en la red.

Algunos de los objetivos planteados para la investigación fueron: 1. La pregunta por los juegos de poder en la cibercultura. 2. Responder a la pregunta acerca de ¿cómo se enmarcan estos juegos y cómo el lenguaje es generador de lazos sociales, nuevas formas de sociabilidad y construcción de la subjetividad? En el presente artículo se enunciarán sólo algunos de los conceptos que configuran el marco teórico de la investigación; entre ellos: Cibercultura, política del lenguaje, literacidad.

El lenguaje, traspasado por los dispositivos informáticos, ha generado nuevas reglas en los modos de leer y escribir en la red, evidenciando la relación entre tecnología, sociedad y cultura propuesta por Escobar (2005), que a su vez, como señala el autor, permitiría considerar los efectos históricos y geográficos actuales del Capitalismo y de la Modernidad; ya que tal como lo plantea Guattari (2005, p. 43), el capitalismo mundial integrado (CMI): "no respeta las territorialidades existentes: tampoco respeta los modos de vida tradicionales, como los de la organización social (...) recompone tanto los sistemas de producción como los sistemas sociales en sus propias bases".

Siguiendo la línea de análisis de las transformaciones en el orden cultural, Escobar (2005), afirma, cuando se refiere a las prácticas escriturales, que existe poca exploración acerca de la transición a una sociedad post-escritural facilitada por las tecnologías de la información. Si la escritura y sus modos de pensamiento reemplazaron la oralidad y las formas situacionales de pensar, la era de la información digital podría estar marcando un distanciamiento de la escritura como tecnología intelectual dominante. Especialmente con la emergencia del lenguaje de la informática.

Stiegler (2002, p. 207), afirma que con la informática hay una modificación de las condiciones de transmisión de los saberes: se pasa de una elaboración-transmisión en "tiempo diferido" a una transmisión-elaboración en "tiempo real". La informática como dispositivo es el valor de la información hecha posible gracias al desarrollo de estas tecnologías, en tanto elementos del dominio de la velocidad, mediante el tratamiento y la transmisión de señales grabables y almacenables en soportes de memoria. La "desterritorialización" se convierte en el horizonte de la decisión política, afectando poderes políticos y económicos, saberes teóricos y prácticos y memorias. (p.162).

Nos instalamos en la perspectiva política del lenguaje, en la que Lazzarato (2007, p. 21), señala cómo el poder del lenguaje se instala en la teoría de los actos de habla de Austin: "la obligación instaurada por el discurso, es decir, la potencia de hablar, la potencia de transformación, de creación propia del lenguaje". Este autor, siguiendo los estudios de Guattari, invierte el punto de vista de la lingüística y de la filosofía del lenguaje, haciendo de la enunciación el "núcleo activo" de la creatividad lingüística y semiótica; plantea Lazzarato, que la enunciación no es un simple derivado de las estructuras gramaticales o sintácticas, una simple realización "individual" del fenómeno "social" de la lengua.

La voz y el engendramiento de la palabra constituyen la raíz enunciativa de los procesos de subjetivación, es decir, las condiciones de emergencia de la subjetividad, y éstas encuentran su origen en un campo de intensidades afectivas anterior a cualquier significación y a cualquier representación. Por estas razones, la naturaleza de la enunciación no es dialógica sino "estratégica": "El acto de habla es una acción sobre acciones posibles a partir de la dimensión ético-política y afectiva de la relación con el otro". La perspectiva es entonces, encontrar formas de libertad dentro de ese modelo de comunicación, formas de actuar, posibilidades de construir procesos de creación en lugar de sometimiento o subordinación.

Siguiendo la perspectiva crítica de la investigación, citamos el trabajo de Derrida, quien plantea a partir de la deconstrucción de la lingüística de Saussure, toda una herencia eurocéntrica del lenguaje no como un asunto meramente fonético, sino que, como la lingüística, situaba su objeto de estudio en el habla, disponiendo 
la escritura como un asunto derivado, externo. La idea de Derrida es pensar la escritura como algo constitutivo del juego de lenguaje: "La escritura no es secundaria ni accesoria respecto al lenguaje, sino que le es esencial" (Peretti, 1989, p. 84, citado por Barreto 2011, p, 91). En palabras de Rueda (2005), se trata de la emergencia de un:

Lenguaje picto-ideo-fono-gráfico, que se aleja de todo centramiento de lo textual, cuestionando el logocentrismo, en el cual el texto se ha encarnado en nuestra cultura. [E] ciberespacio está compuesto de huellas, en tanto] todos los significados tienen detrás una huella, que a veces son años de significado y de retraducciones de este significado, de re-contextualizaciones culturales, de heteroglosias, que se incorporan en la cultura, pero sobre las cuales no nos hacemos conscientes (pp. 3-5).

Los estudios de la literacidad desarrollados por Zabala (2004), revelan la emergencia de un concepto de escritura asociada más con la oralidad, sus efectos en el pensamiento y en la movilidad social, sus usos en diferentes contextos socioculturales, su vínculo con el poder y su impacto en el plano discursivo del lenguaje, que con los procesos cognitivos y de aprendizaje tal como vienen pensados por la Escuela.

En los Nuevos Estudios de Literacidad (NEL), la idea central es examinar los contextos sociales, culturales y políticos que enmarcan la vida de los sujetos. En tal sentido, la escritura está asociada con lo que la gente hace y se localiza en el espacio entre el pensamiento y el texto, la literacidad se localiza en la interacción interpersonal, su interés es indagar las actividades sociales y los textos utilizados por éstas, cómo un determinado grupo usa la escritura en la vida diaria.

Consideramos entonces que la escritura, específicamente la "escritura diaria", está asociada a nuevas formas de socialidad; por ende, tal como la plantea Maffesoli (2011, p. 254), MySpace o Facebook son declinaciones del juego de imágenes y del gasto improductivo, pero justamente en lo inútil del "chatear", en la falta de interés del Blog, parece reencontrarse la consolidación del vínculo social; así, "lo virtual de las ciberculturas es una manera de expresar el deseo de estar conjuntamente".
En tal sentido, estas prácticas aseguran una cohesión social cuyas consecuencias no se han valorado por completo, es por ello que Maffesoli advierte sobre la importancia de poner atención al imaginario lúdico u onírico que atraviesa de una parte a otra la cibercultura, principalmente porque los movimientos en la red se explican más por una energía y una pulsión vital, en otras palabras, un querer vivir irreprimible antes que un razonamiento.

\section{Metodología}

Se trata de una investigación descriptiva y exploratoria en la que se planteó un trabajo etnográfico a partir de la experiencia de los sujetos en la red, enfoque que permitió la expresión de sus emociones, intereses y saberes, a partir de su condición de sujetos "ciber". En tal sentido, no se trató de una "etnografía aplicada a la web", tal como lo plantea Cannevacci, (2004).

Sin embargo, el trabajo de investigación significó preguntarnos por las implicaciones de investigar en el ciberespacio. Rueda, R. (2003, p. 134), señala dos aspectos al respecto: el primero, es que el escenario virtual representa nuevos desafíos metodológicos, en tanto es un lugar en el que la gente y las máquinas tienen una nueva relación, donde se puede tomar lo uno por lo otro y en el cual el yo es múltiple y construido a través del lenguaje.

El segundo, es que cibercultura demanda con mayor radicalidad el carácter situado y parcial del conocimiento $y$, por tanto, el enfoque ha de tomar distancia de perspectivas esencialistas que transforman la objetividad en un punto de vista, de una voz o de una verdad válida. En síntesis, se trata de una aventura para conocer mundos menos organizados en torno a ejes de dominación; igualmente, es necesario comprender las tecnologías asociadas a una dimensión política, dado que cualquier decisión técnica redunda en una organización social.

La etnografía en la web puede apoyar un uso multilingüístico, multi-lógico y trans-icónico de la representación digital, que ocurre en un contexto de investigación, experimentación y conflicto, cuyo objetivo principal es la disolución de la lógica de la identidad legitimizada por la cultura occidental en su gnoseología y en su historia política. En otras palabras, en la 
"comunicación web" los flujos estéticos, cognitivos y visuales son multilineales, multiperceptivos, además de multisensuales, y corresponden con identidades postduales y alteradas, cuerpos táctiles y retractiles.

En el proceso de recolección de información se utilizaron dos estrategias de investigación: la encuesta y la entrevista focal. Consideramos, compartiendo la propuesta de Hyland (2003), citado por Roux (2008), que las encuestas son útiles en los estudios exploratorios de lo que sucede en el contexto de la escritura, ya que permite identificar los aspectos a los que se puede dar seguimiento a través de otros métodos de mayor profundidad, que para este caso fue una entrevistas focal.

El cuestionario contempló los siguientes ítems: datos de identificación, acceso y uso tecnológico, aplicación de herramientas Web (redes sociales, blogs y pdfs) y un último punto sobre percepciones.

\section{Ficha Técnica}

Universo de estudiantes:

800 alumnos estudiantes de Licenciatura en Pedagogía Infantil. Universidad Distrital Francisco José de Caldas.

Población promedio con acceso a internet: Aproximado: 400 estudiantes.

Muestra: 40 estudiantes.

Perfil de los estudiantes:

Tener facilidad de acceso a internet.

Navegar como mínimo tres veces por semana. Hacer parte de una red social. Tener experiencia con blogs.

Localización de los estudiantes: Cinco (5) estudiantes de los siguientes Semestres: $1,2,4,5,6,7,8,10$.

La entrevista focal fue considerada como una estrategia que propicia el debate abierto, accesible de todos y con la posibilidad de recoger intereses comunes, en donde las discusiones toman la forma de un intercambio de visiones, ideas y experiencias que bien pueden ser expresadas de manera emocional, pero en las que no se privilegia ninguna posición. Este tipo de entrevista es útil para comprender las actitudes, las creencias, el saber cultural y las percepciones de una comunidad (Gaskel 2002, p, 191, citado por Bonilla, 1997).
Las preguntas estuvieron dirigidas a ahondar en las motivaciones, intereses, saberes y posiciones, sobre todo en aquello que acontece en el ciberespacio. El grupo estuvo compuesto por tres docentes participantes del proyecto, dos co-investigadoras, un observador y el grupo de 10estudiantes. La entrevista tuvo una duración de tres horas.

Para el análisis de la encuesta se usó un método combinado que permitiera presentar los resultados cuantitativos y cualitativos; en el primer caso del método se recurrió a la cuantificación de datos con ayuda del computador, ilustrándolos con gráficos y tablas, además de la elaboración de matrices para el análisis de las respuestas abiertas. Para la entrevista focal se hizo una transcripción y un análisis, para luego efectuar la descripción de los enunciados principales, así como el chequeo y la corrección de contenido.

Este proceso permitió la agrupación de temas claves para el inicio de la codificación, entendida como una estrategia analítica que, de acuerdo con Coffey y Atkinson (2003, p. 34), resalta tres fenómenos relevantes: identificar los fenómenos; recoger ejemplos de éstos, y analizarlos para encontrar los rasgos comunes, los diferentes, los patrones y las estructuras. Los gráficos y mapas conceptuales fueron útiles para identificar y reordenar los datos y para pensarlos de nuevos modos; aspecto en el que es clave la interpretación a la luz de las teorías y conceptos, permitiendo así más posibilidades analíticas.

En este sentido, experimentamos que la codificación significa mucho más que asignar categorías a los datos, pues se trata de conceptualizarlos y plantear preguntas, logrando así la emoción de la conceptualización fundamentada, tal como la plantea Strauss (1987, citado por Coffey y Atkinson 2003, p. 37). Desde el punto de vista de la escritura, quisimos mezclar la escritura académica con la escritura oralizada, que produce la entrevista focal, rescatando especialmente el testimonio, el diálogo y la narración, géneros que permiten que el sujeto investigado participe con su voz para dar cuenta de aquello que se investiga y producir otros sentidos

\section{Resultados}

Iniciamos con los resultados de la encuesta y luego mostramos los de la entrevista. 


\section{Datos generales de la encuesta}

\begin{tabular}{|c|c|}
\hline Ítems & Descripción \\
\hline 1. Datos de identificación & $\begin{array}{l}\text { Promedio de edad de } 22.8 \text { años, siendo la mayor de } 25 \text { y la menor de } 19 \text {. Se } \\
\text { entrevistaron participantes de todos los semestres (I a X); sin embargo, las estu- } \\
\text { diantes con mayor participación, en términos de una mejor resolución de todas } \\
\text { las preguntas, fueron las de IV S, seguidas de las de IX, VIII, VII y VI. Los demás } \\
\text { semestres (III, III, IV, V, tuvieron una menor participación, quizás esto obedeció } \\
\text { a una mayor experiencia en las redes. }\end{array}$ \\
\hline 2.Acceso y uso tecnológico & $\begin{array}{l}\text { El } 48 \% \text { de la población presenta un gran interés por los avances tecnológicos; } \\
\text { el resto, un } 52 \% \text { demostró poco interés. En cuanto a la disponibilidad del inter- } \\
\text { net se encontró que el } 58 \% \text { manifestó tener acceso a la red en la Universidad, } \\
\text { mientras que el resto de la población de estudiantes tiene acceso desde su casa } \\
\text { el } 23 \% \text {, y del hogar el } 19 \% \text {. }\end{array}$ \\
\hline $\begin{array}{l}\text { 3.Tenencia y uso de aparatos } \\
\text { tecnológicos }\end{array}$ & $\begin{array}{l}\text { Los elementos más frecuentemente utilizados son el celular y el internet; segui- } \\
\text { dos de cámaras digitales y de reproductores MP3. En cuanto al uso de platafor- } \\
\text { mas virtuales, las más empleadas son las redes sociales, seguidas de los Blogs } \\
\text { y los Pdfs. Entre los recursos con menor índice de uso se encuentran los Wikis, } \\
\text { foros, y moodle/blackboard. }\end{array}$ \\
\hline $\begin{array}{l}\text { 4. Aplicación de herramientas } \\
\text { Web }\end{array}$ & $\begin{array}{l}\text { La mayoría de las estudiantes utilizan la red social Facebook ( } 56 \% \text { ), seguida } \\
\text { por Msn, Myspace, y una minoría tiene Twitter. La frecuencia de uso es diaria } \\
\text { para un } 60 \% \text {, mientras que el porcentaje restante permanecen un día, dos o tres } \\
(40 \%) \text {. Las principales actividades realizadas en las redes son chatear, ver fotos, } \\
\text { comentar, jugar, escribir a los amigos, opinar, leer mensajes e información de } \\
\text { interés y relacionarse con familiares. Se registran como actividades menores } \\
(40 \%) \text {, el uso de agenda, la participación en grupos, música, subir y ver videos }\end{array}$ \\
\hline
\end{tabular}

La mayoría de los estudiantes (81\%) son usuarios de Pdf, el resto (19\%), afirma que su uso es ocasional. $78 \%$ de la población Consulta temas académicos, legales e investigativos, mientras que se presenta un menor índice para la literatura y religión (22\%). Los estudiantes acceden a un Pdf considerando preferiblemente la fidelidad de la fuente y la profundidad en el tratamiento de los temas (67\%); otros criterios menos importantes son acceder y compartir el conocimiento y encontrar bibliografía (33\%). La frecuencia de uso se divide en un $50 \%$, que lo hace de manera casual y un $50 \%$ que utiliza este recurso de manera frecuente. El 68\% consulta los Pdf de carácter científico y académico, mientras que el $32 \%$ lo hace para literatura, artículos de revista y libros en general.

Una gran mayoría (82\%), de los estudiantes tiene claro que este tipo de documento se escribe para un público en general y para pares académicos; mientras que un $18 \%$ considera que se puede tener como objetivo a cualquier persona. La población ve la escritura de estos documentos como diversa y formal, los considera numerados, sin errores ortográficos, confiable, extensa, seria, ordenada y clara. Es completa. También observa que la letra es adecuada, con temas argumentativos, de fácil comprensión. En cuanto a los géneros más solicitados son libros completos, cuentos, reseñas, ensayos, cartillas, música, artículos, ponencias, proyectos personales, resúmenes.

Los usos de la lectura y escritura para este formato revelan unas operaciones de lectura y unas facilidades que demuestran, por una parte, una práctica de estudio que revela nuevas apropiaciones del saber y, por otra, variadas posibilidades de acceso a la información; el proceso hizo evidente un aprendizaje de la técnica que facilita cada día más el acceso. Finalmente, una descripción de las dificultades da cuenta del proceso de adaptación a estas nuevas formas de lectura. En cuanto a las funciones, se encontró una tensión entre la información y el saber, que se enumera a continuación:

En cuanto al formato de Blogs, se observa un avance en el desarrollo de la escritura corta, concisa, breve, 
sintética, clara, directa y con buena presentación, es una escritura argumentativa y descriptiva, con uso de gramática y ortografía. Puede ser también científica, cultural y social; utiliza un lenguaje simple, es detallada y respetuosa; igualmente, se lee con atención y desde una mirada crítica de usuario, mientras que se escribe en forma de comentario.

Se experimenta una práctica de la escritura como experiencia interactiva y colaborativa, se escribe lo que se piensa de verdad, con una lectura y escritura a partir de conocimientos previos, se espera aprobación o desacuerdo frente a lo escrito, ya que se cuenta con la opción de comentarios y de brindar ayuda a la gente. La escritura está enfocada en un tema y permite el intercambio de conocimiento e información; también ofrece la posibilidad de compartir lo que se piensa de una manera detallada. Genera la lectura y escritura del texto multimedial, al acceder a libros, artículos, videos, poesía, música, fotografías, cuentos y noticias. Las imágenes permiten comprender la realidad, los video-clips van más allá, posibilitan el reconocimiento de un tema sin explicaciones previas, las fotografías permiten reflexionar sobre la experiencia, dan contexto a la información, recrean el texto y dan a entender las acciones.

En cuanto al uso estratégico en redes sociales, la mayoría de las estudiantes pertenecen a la red social de Facebook (56\%), sigue Msn, My Space, y una minoría tiene Twitter. La frecuencia de uso es diario para un $60 \%$, los demás están un día, dos o tres $(40 \%)$. Las principales actividades realizadas en las redes son chatear, ver fotos, comentar, jugar, escribir a los amigos, opinar, leer mensajes, informarse sobre intereses particulares y relacionarse con familiares. Se registran como actividades menores (40\%), como el uso de la agenda, participar en grupos, música, subir y ver videos.

La mayoría de la población (55\%) piensa que la escritura es no-formal, sin ortografía, y que se trata de una escritura corta. El porcentaje restante percibe que se usan diminutivos y se incluyen otros caracteres o imágenes (45\%). La narrativa (37\%) es el género que se utiliza con mayor frecuencia, seguida de la argumentación $(28 \%)$, la forma dialógica $(27 \%)$ y, muy pocas descripciones (8\%). En cuanto al material escrito por la población, la mayoría se enfoca en pensamientos, comentarios y eventos cotidianos y emociones (72\%), mientras un $28 \%$ anota chistes, chismes y opiniones
(28\%). La mayoría de los estudiantes tiene como destinatario de lo que escribe para sus amigos y contactos y familiares (86\%), y en menor medida, se escribe a familiares, profesores y compañeros (34\%).

Analizando la arquitectura de Facebook, Ilama la atención el uso del muro, los perfiles, las noticias/inicio de sesión y las publicaciones (73\%), que son seguidos en menor medida, por la utilización de afiliaciones, invitaciones y palabras clave (37\%). La población se inclina hacía la observación de imágenes (68\%), antes que por la de fotos, que ocupa sólo un 32\%. Sin embargo, las fotos son el elemento que más se "sube" a la red para compartir con personas conocidas, les sigue la música con $61 \%$ y en menor porcentaje se comparten comics y dibujos.

Esta tipo de acciones se realizan gracias a un interés general por socializar experiencias personales y para generar interpretaciones (57\%), en menor medida por diversión, moda o por simple solicitud de amigos (47\%). Los resultados de las respuestas de la encuesta permiten ver que las redes sociales efectivamente están generando transformaciones en la estructura y significado de la cultura y la sociedad moderna, en las que el saber, la socialidad y las formas de acceder al conocimiento, se mueven en fronteras menos rígidas.

Los resultados del análisis de la entrevista presentan cuatro grandes categorías de usos:

\section{La lectura y la escritura diaria}

Se presenta como el fenómeno principal, lo desglosamos en tres temas: crear nexos emocionales, hacer amigos y simular identidad. Desde la perspectiva del poder, los usos estratégicos de la lectura y la escritura diaria en la red, especialmente en Facebook, plantean una orientación volitiva y emotiva en la esfera dialógica de la construcción de una nueva forma de socialidad, regulada por la arquitectura, que permite modular las percepciones de los usuarios a través de estrategias de influencia social, como: los Ilamados morales, los saludos o los pedidos directos.

También se señala la facilidad para aceptar invitaciones, el ciclo rápido que genera motivación y entusiasmo, y el impacto medible entre otros. La agresión expresa sentimientos de rabia furia e irritación, los autores buscan la aceptación de otros a través de las publicaciones del muro, acción o lección que regula los compor- 
tamientos; aprendizajes importantes, que empiezan a demandar nuevas formas para la actuación como sujetos colectivos.

Yo tengo acceso a todas mis amistades, entonces digamos yo tengo 200 amigos, a veces, todo lo que va sucediendo en el muro de una persona va a llegar al tuyo, entonces, tú te das cuenta de qué están escribiendo los otros, a quién le están escribiendo, a quién le están escribiendo cosas ofensivas, y qué está sucediendo con todos esos amigos que yo tengo, todo eso tiene que ver en estructuras como tu red.

Se observa entonces que los usos estratégicos de la escritura diaria se hacen para saber que está haciendo la gente, saber de su vida. Se producen a través de la interacción con los enunciados escritos en muros, por haber sido etiquetados en fotografías o por comentarios. Son relaciones directas calificadas como amenas y generalmente se hacen y se consolidan en espacios de la vida real. Los amigos que se conocen por primera vez pueden conducir a situaciones nuevas de experimentación.

\section{Aprender los usos estratégicos de la lectura y la escritura en la red}

- Los resultados permiten concluir que los estudiantes rechazan las alteraciones de la escritura, según la población, este es un fenómeno de los niños entre 12 y 14 años, quienes son los que más disfrutan de estos cambios.

- La población aceptan que la forma de escritura está asociada a un problema de identidad.

- La escritura abreviada es una disposición de la arquitectura de Facebook, a la que la población se han visto sometida; sin embargo, pueden sentirse libres al hacer cosas simultáneamente, al mismo tiempo que están en esta red social, pueden trabajar en la red haciendo otras cosas;

- Cambiarse el nombre en el perfil, simular identidades, por ejemplo con fotos, es visto como algo "raro"; consideran que en la red se puede construir una identidad "propia".

- Facebook se caracteriza por ser un espacio de múltiples usos estratégicos. El comentario permite conocer mucho a las personas, con los pensa- mientos se puede adquirir prestigio, y la escritura diaria, escribir lo que pasa, lo que deja el día, da la impresión a la población de que se está con otros.

- La escritura en este espacio, permite adquirir un estilo propio, capturando así elementos del lenguaje o del habla, de la imagen o de la fotografía, que posibilita expresar con mayor precisión sus acuerdos, desacuerdos, simpatías, antipatías o adhesiones.

\section{La multiplicidad. Acciones estratégicas para la reproducción de los sentidos}

Ingresar, ir, abrir, revisar, interactuar, subir, bajar, chatear, son términos que expresan acciones-movimiento en las que la lectura y la escritura juegan un papel fundamental. Movimientos en el ciberespacio en los que el sujeto aprende a manejar su conexión con propósitos diversos y que pueden ser realizados al mismo tiempo. Practicar un idioma, hablar con un amigo, cuidar a los hermanos, oír música, ver un video, subir un escrito. Son flujos estéticos, cognitivos y visuales que transitan de maneras múltiples; como lo señala Rueda (2003), estos espacios pueden ser comprendidos para la compensación -sentirse mejor-, para la participación, sencillamente, -estar con otros-, o para la resistencia -realizar acciones políticas-. Todo esto parece ocurrir en la red.

\section{Uso de la fotografía en el perfil. Acciones y aprendizajes}

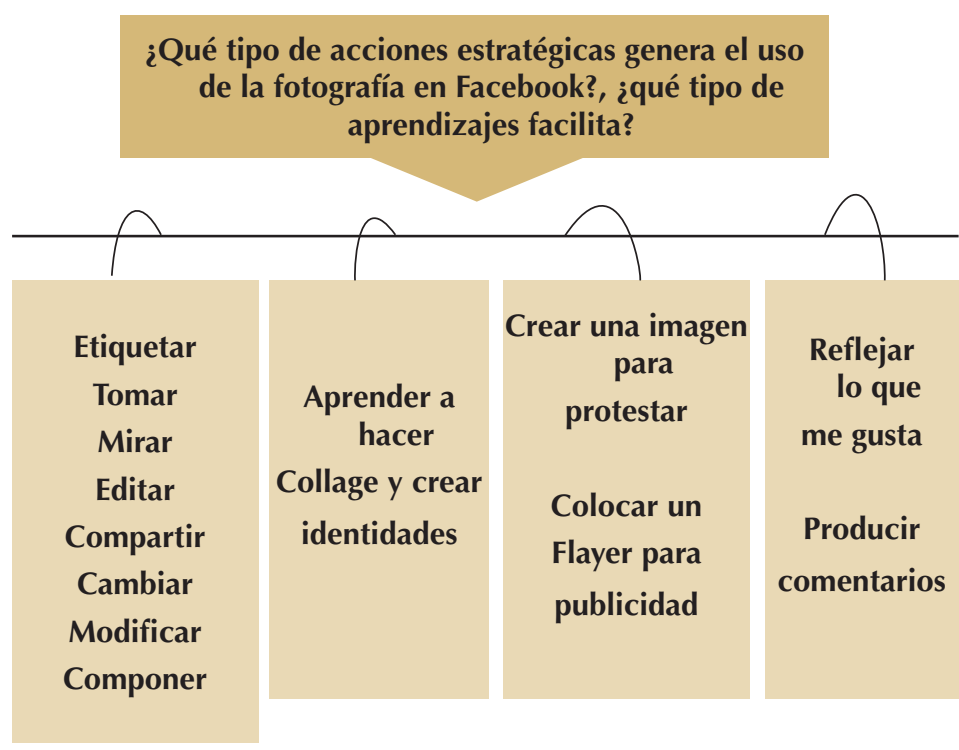


La fotografía en el perfil crea un espacio dialógico que opera como la lectura y la escritura. En su calidad de enunciado, es un acto donde la subjetividad se apodera para crear significaciones materiales y vínculos verbales, creando emociones, así como posiciones ético políticas; en otras palabras, se refleja todo el impulso interno. Como elemento no discursivo, genera un sentido físico de la palabra: se esperan los comentarios, respuestas que expresan adhesiones, manifestaciones de acuerdos o desacuerdos. En tal sentido, los usos estratégicos de la fotografía crean un espacio para el ejercicio relaciones de poder, en tanto que no se actúa sobre otros, sino sobre sus acciones al etiquetar, editar, modificar o componer las imágenes.

Con la fotografía se juega a modificar las conductas de los otros, haciendo la publicidad, creando identidades. En este mismo sentido, permite a la población tener un estilo propio a través de las posibilidades que ofrecen los programas de edición de fotos. Nuevos aprendizajes para jugar con sus identidades, manifestar afectos, o generar antipatías.

\section{Conclusiones y recomendaciones}

En cuanto al uso de los documentos pdf, la experiencia de las estudiantes hizo evidente que la lectura y la escritura en la red están mostrando una nueva forma de apropiación del saber, facilitada por el uso de tecnologías de la comunicación y la información: por una parte, se produce un mayor acceso a la información en red que pone en juego imágenes, sonidos y texto; por otra, se abren las posibilidades para la transmisibilidad del saber a partir de los usos estratégicos de lectura y escritura. Los estudiantes generan acciones de estudio y aprendizaje como el sustentar, argumentar, conocer, enseñar, trascender, publicar, compartir, comprender. Igualmente, se observa la apropiación de las reglas de juego con las que operan estos sitios, que permiten conseguir información y obtener ganancias económicas.

En cuanto al formato del Blog, se encontró que los estudiantes han interiorizado la práctica de escritura, lo que revela una evolución muy sensible de los procesos lecto-escritores. La escritura como experiencia interactiva y colaborativa, deja ver cómo se ha dado un uso estratégico de la comunicación que permite la producción de un saber compartido y la lectura y escritura del texto multimedia, en el cual se muestra la apropiación de nuevos aprendizajes para la producción y edición de imágenes y videos.

En Facebook lo constitutivo de los enunciados, chatear, subir un escrito a un blog, hablar a un amigo, son acciones que están dirigidas a alguien, responden a alguien, expresan valores, puntos de vista, emociones, afectos, simpatías. Ello es posible también por la variabilidad de uso de la lectura y escritura; se pasa simultáneamente de la escritura diaria, el saludo, a subir un escrito a la página de monografías o a escribir frases en el aprendizaje de un idioma. Escrituras y lecturas que se mutan para provocar múltiples acciones. La escritura diaria, tiene que ver con resolver el día a día, despertando la emocionalidad y curiosidad de los interlocutores, un uso estratégico para el aprendizaje a partir de una participación paulatina en situaciones de uso contextualizado del discurso. La escritura se hace formal y abierta, sencilla, puntual, directa, rápida, abreviada, coloquial.

Es posible concluir que los usos de lectura escritura, para individuos como los estudiados, jóvenes y estudiantes universitarios, han permitido diversificar el uso de los diferentes lenguajes (oral, escrito, imagen, fotografía) para hacer amigos, conocer mejor a los otros; al tiempo, todas estas acciones, están dirigidas a una afirmación de subjetividades asociadas con los dispositivos propios de las instituciones, como la escuela, la familia, donde se busca fortalecer una identidad; en tal sentido, el uso de la lectura en la red se convierte en un aprendizaje que implica procesos de adaptación a las nuevas exigencias de lectura y escritura, que demandan una mayor flexibilidad de sus formas de ser $y$, por supuesto, el tránsito a otras subjetividades.

Por tanto, las acciones estratégicas de lectura y escritura entran a hacer parte de la cadena de enunciados propios de los agenciamientos de enunciación de la sociedad disciplinaria, antes que de los de la sociedad de control. Es posible que su práctica, ligada a procesos de reflexión generados por la academia, permitan cada vez mejores actuaciones en la red.

Es necesario revisar los efectos históricos y geográficos actuales del Capitalismo, y hacer énfasis en la forma en que la relación entre las máquinas y los sujetos sociales permite situar al sujeto como productor de discurso, y de cómo la comunicación mediada por el computador 
efectivamente, genera nuevas formas de subjetividad. Desde la perspectiva del poder, los usos estratégicos de la lectura y la escritura diaria en la red, especialmente en el Facebook, plantean una orientación volitiva y emotiva en la esfera dialógica de la construcción de una nueva forma de socialidad, regulada por la arquitectura, que permite modular las percepciones de los usuarios a través de estrategias de influencia social, como: los Ilamados morales, los saludos, los pedidos directos.

Entonces, desde el punto de vista comunicativo, los usos estratégicos de lectura y escritura en la red operan con la huella y la fuerza que le otorga un poder creativo a la relación sujeto-máquinas. Nos hallamos en sistemas discursivos, pero al mismo tiempo tenemos que crear focos de afirmación de existencia. Esta es la paradoja que nos plantea Guattari, son la voz y el engendramiento de la palabra, los que constituyen la raíz enunciativa de los procesos de subjetivación; pero además lo constitutivo del enunciado, o acto de habla, es que se dirige a alguien, responde a alguien, expresa valores, puntos de vista, emociones, afectos, simpatías, antipatías.

Finalmente, dado que la investigación se realizó en el contexto universitario, concretamente en el marco del proyecto curricular de pedagogía infantil, consideramos de vital importancia pensar los retos de la Universidad frente a la llamada revolución digital, propia del desarrollo Capitalismo Integrado, nuevo régimen de acumulación globalizada en la producción de conocimientos, Ilamada hoy la sociedad de la información.

Según lo planteado por Brunner (2001), es necesario partir de un análisis de los cambios que experimenta nuestra relación con el conocimiento, que tienen que ver con la velocidad en la renovación del saber, la naturaleza del trabajo, y por tanto, se impone a la universidad el reto de reorganizar las formas de generación de conocimiento para lograr mejores niveles de interconectividad, movilidad, así como de ideas, información, conocimientos, productos y servicios; en otras palabras, reconocer las ventajas de operar en red, lo cual implica el desarrollo de relaciones flexibles, sin centro fijo, multidireccionales, de alta velocidad y alcance global.

Para terminar, exponemos algunas recomendaciones para pensar la educación virtual en la Universidad.
- Mantener la diferencia entre saber e información, que ha caracterizado la educación presencial.

- Partir de los saberes y experiencias de los estudiantes.

- Integrar el potencial afectivo que está generando el trabajo en redes.

- Reconocer los procesos de informalidad que caracterizan al ciberespacio

- Reflexionar desde una perspectiva crítica la emergencia de la cultura "digital".

\section{Referencias}

Barreto, R. M. (2011). De la deconstrucción del signo lingüístico a la escritura como huella en Jacques Derrida. [Tesis de maestría]. Bogotá: Pontificia Universidad Javeriana, Maestría en Filosofía.

Bonilla, E., y Rodríguez. (2000). Más allá del dilema de los métodos. Bogotá: Grupo Norma.

Brunner, J. J. (2001). La educación al encuentro de las nuevas tecnologías. Obtenido en Abril de 2012, desde http://archivos. brunner.cl/jjbrunner/archives/JJ_IIPE_BA_4.pdf

Cannevacci, M. (2004-Octubre). Etnografía Web e identidades avatar. Revista Nómadas, 21. Bogotá.

Cassany, D., Sala, J., y Hernández, C. (2008). Escribir "al margen de la ley". Prácticas letradas vernáculas de adolescentes catalanes. Barcelona: Universitact Pomper Fabra. Obtenido desde http:// elvira.IIlf.uam.es/clg8/actas/pdf/paperCLG21.pdf

Coffey, A. (2003). Encontrar el sentido a los datos cualitativos. Medellín: Universidad de Antioquia.

Escobar, A. (2005). Bienvenidos a Cyberia. Revista de estudios sociales, 22, 15-35.

Guattari, F. (2005). Plan sobre el planeta. Capitalismo mundial integrado y revoluciones moleculares. Bogotá: Ediciones desde abajo.

Hardt, M. (2010). Trabajo afectivo. Obtenido en Julio de 2012, desde http://www.cinosargo.cl/content/view/852655/Trabajoafectivo-por-Michael-Hardt.html

Lazzarato, M., y Negri. (2001). Trabajo inmaterial. Formas de vida y producción de subjetividad. Obtenido en Marzo de 2012, desde http://www.rebelion.org/docs/121986.pdf

Lazzarato, M. (2007). ¿Poder del lenguaje o creación? La filosofía de la diferencia y el pensamiento menor. Cátedra inaugural de la Maestría en Investigación en Problemas Sociales Contemporáneos. Bogotá: Eds. Universidad central, IESCO-UC, Fundación comunidad, 17-43.

Lazzarato, M. (2007). Cibercultura. Informe al Consejo de Europa. España: Anthropos.

Maffesoli, M. (2011). "Ciberespacio y masturbación: una comunión postmoderna de los santos". en Sanabria, F. (Comp.). Vínculos virtuales. Bogotá: Universidad Nacional de Colombia, 249-260. 
Rueda, R. (2003-Mayo). “Tecnologías informáticas: Herramientas, metáforas y espacios culturales de investigación. Revista Nómadas, 18.

Rueda, R. (2005). "Apropiación social de las tecnologías de la información: Ciberciudadanías emergentes". [Ponencia]. Universidad Autónoma de Occidente. Cali Colombia. Obtenido desde http://firgoa.usc.es/drupal/node/23700

Rueda, R. (2008-Abril). "Cibercultura: metáforas, prácticas sociales y colectivos en red". Revista Nómadas, 28. Bogotá.
Roux, R. (2008). "Prácticas de alfabetización académica: Lo que los estudiantes dicen de la lectura y la escritura en la universidad". En Cardona, E. (2008). Los desafíos de la lectura y la escritura en la Educación Superior. Caminos posibles. Cali: Universidad Autónoma de Occidente.

Stiegler, B. (2002). La técnica y el tiempo. Tomo I. El pecado de Epimeteo. Madrid: Ministerio Francés de Cultura.

\section{Diálogo del conocimiento}

Plantear la necesidad de aportar a la configuración de una nueva crítica de la tecnología educativa en donde se problematizar las relaciones entre ciencia, tecnología y sociedad, es evidenciar como la cibercultura se encuentra asociada con agenciamientos de vida, trabajo y lenguaje que favorecen a la disposición de nuevas formas de subjetivación en donde el sujeto es productor de discurso y la comunicación en las redes genera nuevas formas de subjetividad. $\mathrm{Al}$ Preguntarse por los juegos de poder en la cibercultura se da cuenta de las formas como el lenguaje genera lazos sociales, formas de sociabilidad y construcción de la subjetividad y la sociedad, así como de distintas formas de abstracción y representación del mundo (Ruiz, J. I; 2001), modos de actuación social en donde emanan nuevos sueños e imaginarios (Silva, A; 2004). Dimensión que hace posible comprender como las representaciones sociales dejan al descubierto algunos cambios culturales vinculados con los procesos contemporáneos de la globalización donde se visibiliza que la acción tecnocientífica genera un marco de creencias, intereses y valores, en el entramado social y cultural (Baeza, M. A; 2000).

Las nuevas configuraciones sociales están saturadas de múltiples maneras de vivir y convivir en la sociedad contemporánea, en donde la influencia y el acelerado uso de equipos y dispositivos tecnológicos suscitan diversidad de modos de integración y disgregación entre los actores sociales que participan en la vida cotidiana. Esta dinámica encierra una variedad de prácticas, representaciones y valores sociales que estructuran las culturas emergentes (Medina, 2011) En ellas, no sólo basta la comprensión de la diversidad cultural y de los contextos heterogéneos sino que demanda reconocer y comprender las lógicas particulares con que actúan las diferentes propuestas emergentes que surgen como respuesta frente a la tendencia de homogeneización y al dominio que impone el desarrollo de la globalización como lo señala García Canclini (1990) y provocan un impacto importante en las dinámicas sociales del presente por medio de nuevas formas de representación social que es prioritario identificar (Moscovici, S.1981).

Frente a tales impactos Lavolpe (2007) destaca que "La revolución tecnológica ocurrida en las últimas décadas, en especial en el campo de la información y las comunicaciones, profundizó las relaciones políticas, económicas, sociales y culturales del mundo, mediante su generalizada aplicación a la producción, las finanzas y el conocimiento. La dinámica de la globalización se expresa en el incremento, en intensidad y frecuencia, de las relaciones entre estados, empresas, grupos culturales, individuos, organizaciones no gubernamentales, instituciones educativas, etc.

Estas "relaciones interdependientes" se establecen a través de vínculos comerciales, culturales, políticos y educativos. A su vez, los canales muestran nuevas formas y modalidades de relación, donde el desarrollo tecnológico juega un papel relevante en el crecimiento y la velocidad del proceso. Es decir, se pone en juego la profundización de la interdependencia en el escenario mundial como producto de una nueva revolución tecnológica. La interdependencia compleja comprende un conjunto de relaciones multidimensionales, caracterizado por la simultaneidad de áreas y sectores involucrados.

Roberto Medina Bejarano 